\title{
Borboletabirinto da poesia de Ondjaki
}

\section{Labyrinth of Ondjaki’s Poetry}

\author{
KATEŘina Ritterová [katerina.ritterova@upol.cz] \\ Univerzita Palackého, República Checa
}

\begin{abstract}
RESUMO
Este estudo pretende mostrar a faceta poética da obra do jovem escritor angolano Ondjaki. Essa característica perpassa por toda a sua obra, tanto na poesia como na prosa, e o objetivo que nós propomos é analisar e mostrar o poetismo desta obra literária. Vamos aqui abordar tanto quanto possível a totalidade da obra poética de Ondjaki, mas mais detalhadamente pretendemos analisar o livro Há Prendisajens com $o$ Xão, que dos que escreveu é talvez o mais marcado pela linguagem experimental, pelos neologismos, pelos jogos de palavras e pela poética livre, quase infantil, próxima da chamada poesia nonsense. Tentaremos mostrar como essa visão do mundo não só reanima as palavras e lhes atribui sentidos completamente novos, como também cria novas realidades, puras e inesperadas.
\end{abstract}

\section{Palavras-chave}

literatura angolana; poesia; neologismo; nonsense

\begin{abstract}
This study intends to show the poetic facet of the work of the young Angolan writer Ondjaki. That characteristic runs through the whole of his work, both in poetry and in prose, and the purpose of this study is to analyze and show the poetics of this literary work. Here we approach as mucu as possible the whoke of Ondjaki's poetic work, but in more detail we intend to analyze the book Há Prendisajens com Xão, which is perhaps, from those he has written, the most imbued with experimental language, neologisms, puns, and free, almost childlike poetry close to nonsense poetry. We will try to show how such vision of the world not only reanimates words and gives them completely new senses, but also creates new, pure and unexpected realities.
\end{abstract}

\section{KEYWORDS}

Angolan literature; poetry; neologism; nonsense

RECEBIDO 2017-03-18; ACEITE 2017-05-23

O artigo foi publicado no âmbito do projeto do Ministério da Educação da República Checa IGA FF 2016 050 (As Literaturas e Línguas Românicas num diálogo transcontinental) 
"A poesia ocupa um lugar de dúvida, na minha escrita. Eu realmente tenho dificuldade em entender a poesia que escrevo, ou as razões por que o faço. Mas por alguma razão que ainda desconheço, continuo a escrever poesia. É talvez importante, para mim, não saber o "porquê" de certas coisas no mundo da literatura".

\section{Ondjaki}

Em umbundu, Ondjaki significa "guerreiro", e é o nome artístico de Ndalu de Almeida, nascido em Luanda em 1977. Diz-se mais prosador do que poeta, mas a sua prosa não deixa de mostrar-se, ela também, muito poética. Depois de uma incursão pelo teatro amador, Ondjaki especializou-se em artes plásticas e participou nalgumas exposições em 1999, em Lisboa, e um ano depois em Luanda e Salvador da Bahia. Licenciou-se em Sociologia e em 2010 fez o doutoramento em Estudos Africanos, em Itália. Foi galardoado com uma menção honrosa do Prémio António Jacinto pela sua primeira obra - o pequeno livro de poesia Actu Sanguíneu. Depois de estudar seis meses em Nova Iorque, na Universidade de Columbia, colaborou com Kiluanje Liberdade e filmou o documentário Oxalá Cresçam Pitangas - Histórias de Luanda. Várias obras suas foram traduzidas para francês, inglês, alemão, italiano, espanhol e chinês. Em 2013, recebeu o Prémio Literário José Saramago pelo seu romance Os Transparentes Atualmente mora no Brasil, no Rio de Janeiro.

É um poeta que se dedica mais à prosa do que à poesia; de vinte e sete obras já editadas só cinco são de poesia: Actu Sanguíneu (2000), Há Prendisajens com o Xão (2002), Materiais para Confecção de um Espanador de Tristezas (2009), Dentro de Mim Faz Sul, Seguido de Acto Sanguíneo (2010), Os Modos do Mármore (2015). O próprio autor mostra uma relação muito especial com a sua poesia, como diz numa de muitas entrevistas:

Faz-se poesia porque se precisa dela, ou de a partilhar. Mas sobretudo fazer poesia é uma necessidade. Nem sempre é fácil publicar um livro de poesia... Porque se pensamos no público, no leitor... Quer dizer, é um género mais complicado, menos acessível, menos fácil. Escreve-se um poema como uma urgência interna, e por vezes há uma estória (mais íntima) por detrás do poema. Mas é preciso aceitar que a poesia é também mistério... Nem tudo é claro, explícito. Faz parte. O que quero dizer é que não sei bem como o leitor vai encarar o que lá está escrito, o que foi dito. Mas de qualquer modo, eu sei, este receio não faz sentido nenhum, cada leitor recebe os materiais de escrita do seu modo e assim funciona a literatura. Escrevo primeiro para mim, sobretudo no caso da poesia, mas tenho receio que os meus poemas por vezes sejam um pouco herméticos ou mesmo chatos. ${ }^{2}$

1 http://homoliteratus.com/entrevista-com-o-escritor-angolano-ondjaki/

2 http://www.buala.org/pt/cara-a-cara/fazer-poesia-e-outros-projectos-entrevista-a-ondjaki 


\section{Obra poética de Ondjaki}

\subsection{Actu Sanguíneu (2000)}

Podemos caracterizar Actu Sanguíneu como um livro da poesia confessional, já que o poeta escreve quase na totalidade na primeira pessoa, fazendo-nos assim facilmente confundir o sujeito lírico com o autor. Apesar de muitas metáforas, personificações e animizações (sendo estas últimas típicas em Ondjaki), a sua poesia é muito fluente, como se de uma narrativa poética se tratasse:

Cego-me de branco, cubro os lóbulos

Com o som que sabe desenhar mundos.

Eu-piano, eu-engano

Cego como as pulgas fugazes do meu cão,

Cego na aprendizagem da bengala

A que chamo chão. (Ondjaki 2010: 83)

Já neste poema mostra o gosto pelos jogos de palavras e de classes gramaticais (eu-piano, euengano podem ser tanto verbo como substantivo), antíteses e oxímoros (cego-me de branco), de sentidos e sensações cubro os lóbulos com o som que sabe desenhar mundos.

\subsection{Dentro de Mim Faz Sul Seguido de Acto Sanguíneo (2010)}

No ano de 2010 resolve editar de novo o seu primeiro livro, Actu Sanguíneu, desta vez com a ortografia retocada - Acto sanguíneo - e enriquecido com três longos poemas novos, reunidos numa coletânea chamada Dentro de Mim Faz Sul. Ele próprio diz sobre este livro:

Actu sanguíneu era uma reunião, talvez extensa, de poemas escritos no fim da adolescência, onde a descoberta de manobras linguísticas se tornara veículo para dizer os mundos que me andavam por dentro. Eram viagens internas que apelavam a instantâneos poema vestidos de cores, cheiros, dores. Ecos do que também andava a ler e a descobrir, e sobretudo pequenas explosões sensoriais que eu buscava controlar por via de palavra corrigida, mil vezes relida. (Ondjaki 2010: 8)

Esta busca insaciável da perfeição poética, às vêzes complicada, digamos labiríntica, mas ligada com a leveza dos cheiros, cores e da própria existência, alude ao nosso título do presente artigo. Trata-se de borboletabirinto da poesia ou da poesia borboletabiríntica. $\mathrm{O}$ facto de que Ondjaki tinha resolvido reeditar a sua primeira colectânea junto com o seu livro mais recente cria um círculo fechado e assim enfatiza a metáfora do labirinto representando a obra de Ondjaki. 
Dez anos depois, resolvi inventar esta pequena celebração. Numa edição especial junto o primeiro livro e o mais recente. Ambos de poesia mas, sobretudo, ambos do mesmo universo de poesia, que são portas que conduzem a um lado mais interno...um lado mais cicatrizado de mim. (Ondjaki 2010: 8)

Esta poesia continua confessional e podê-la-íamos perceber como amorosa, porque, aparentamente, não só os pássaros falam do amor de madrugada:

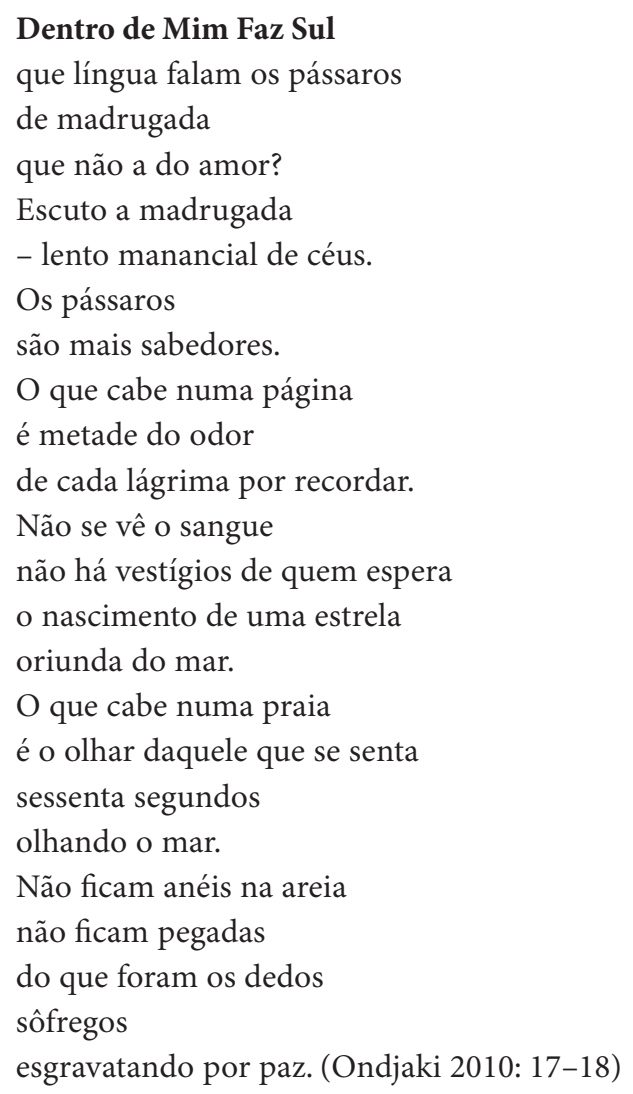

É uma poesia que continua, pois, de forma confessional, mas muito mais entrelaçada com a natureza. Nota-se muito que as sensações atribuídas aos animais e aos outros elementos da natureza fazem sobressair as sensações humanas. Metáforas inspiradas como a madrugada - lento manancial de céus, o nascimento de uma estrela oriunda do mar, intercaladas com uma história de amor, mostram a importância da natureza na vida humana, o que se confirma no verso o olhar daquele que se senta sessenta segundos olhando o mar e se intensifica com a aliteração se senta sessenta, evocando o ruído do mar, enquanto o próprio jogo de palavras simula a repetição. 


\subsection{Materiais para Confecção de um Espanador de Tristezas (2009)}

Materiais para Confecção de um Espanador de Tristezas é, por um lado, um livro mais enigmático, porque marcado por muitas alusões intertextuais, e, por outro, uma obra muito pura, quase cristalina, porque remete para a simplicidade e pureza da infância. Neste livro Ondjaki faz homenagem aos seus poetas amados: Clarice Lispector, Guimarães Rosa, Manoel de Barros, Adélia Prado, Luandino Vieira e muitos outros.

gosto de mãos rupestres

- de infâncias,

de me dobrar e tombar

em risos e estigas que a minha rua já não tem.

chorar - escrevendo um livro depois apagado.

rir - lendo memórias apagadas.

a sujidade da infância tem um cheiro

de barro

e trepadeiras poeirentas.

quando me sujo de infâncias

espirro

um sardão enorme

- e um gato dançado

Pelo tiro da minha pressão-de-ar. (Ondjaki 2009: 52)

A infância funciona como inspiração, como forma de relembrar a arte poética, nos tempos remotos da vida. Repete-se aqui uma metáfora que o poeta utiliza também noutros poemas: uma sujidade positiva - a sujidade da infância: é sujo de infância, tem a boca suja de poesia. Este novo, desautomatizado olhar da realidade vê também Fernanda Coutinho Marlúcia Nogueira do Nascimento como construidor: Nos livros de poesia, como em Materiais para a Construção de um Espanador de Tristezas (2009), a brincadeira com a linguagem e com os "desobjectos" funcionam como instrumento de intervenção poética na realidade. Em um depoimento de abertura ao livro, Ondjaki reconhece a importância da poesia como desautomatização do cotidiano (Nogueira do Nascimento 2014: 102).

A poesia amorosa aparece um pouco inesperada neste contexto, mas o poeta continua muito sincero, confessional, até intimista e quase romântico. Mas, mesmo num poema de amor, continua a fazer parte da natureza e, personificando a pedra, animiza-se:

A mulher

Vou escrever na pedra a palavra amor - inventar uma textura na minha estória pessoal. Há uma ruga na pedra sulcada pela minha lágrima. Se a pedra sorrir vou me esconder no riso dela. Se o vento vier vou alisar o tempo perdido e construir memórias.

Primeiro vou beijar a mulher, depois a pedra.

Se sobrarem beijos, vou atirá-los a favor do vento. (Ondjaki 2009: 51) 
Três repetições da frase condicional remetem para contos de fadas. Mesmo as condições Se a pedra sorrir ou Se o vento vier parecem sair diretamente de algum conto popular. E, na gradação, a conclusão Se sobrarem beijos, vou atirá-los a favor do vento pode ser tanto uma gradação feliz, amorosa, como o próprio fim da relação, assumida na união aconchegante com a natureza.

\subsection{Os Modos de Mármore + 3 poemas (2015)}

No último livro de poesia, Os Modos de Mármore + 3 poemas, a infância deixa de ser um dos motivos prediletos. Aqui é o amor que tem capacidades de reanimar a pedra, de fazer reviver os momentos passados e, como é costume na poesia lusófona, de através da dor fazer crescer e mudar um ser num homem verdadeiro:

O remoinho acendeu-se, as algas revoltaram-se e me afagam como me afundam, o deserto acordado me calcinou, a noite me consumiu e dentro de mim o mármore amadureceu - não me deixa dar-te nem os pedaços de um recado violento, solidificam-se-me as cordas vocais quando tento dizer-te não temos muitos mais dias, amor.

Quando passares por mim, eu sou essa escultura dócil a quem a tua mão afaga o mar de pedra quieta, eu sou todas as folhas secas estaladiças inofensivas amordaçadas. (Ondjaki 2015: 20)

\subsection{Há Prendisajens com o Xão (O Segredo Húmido da Lesma \& Outras Descoisas)}

Escolhemos o livro Há Prendisajens com o Xão com o subtítulo explicativo (O Segredo Húmido da Lesma \& Outras Descoisas) para uma análise mais aprofundada, porque já é habitual percecioná-lo por duas possíveis interpretações: pode ver-se como uma certa expressão de angolanidade na união com a terra, ou como um livro de aprendizagem da vida, do "funcionamento" da natureza, da ligação entre Homem e natureza, como uma explicação do mundo. Ao mesmo tempo é um livro sobre prendisajem - sobre um prendimento, a ligação dum ser a um outro, a referida ligação da natureza ao Homem. A primeira opinião recolhida é de Cristina Muraro:

Para o leitor da literatura angolana, não se trata, porém, da poesia de combate das décadas anteriores. E apesar dos contornos metapoéticos também se realizarem em Há prendisajens como

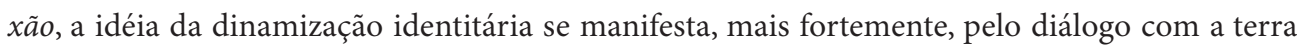
e seus desdobramentos... Mas seria, hoje, possível uma "aprendizagem" da sensibilidade e da emoção por meio da ficção literária em um espaço transfigurado pela herança dos tempos de guerra, como é o espaço angolano? E de que forma a palavra poética, ancorada na infância, lugar da ausência de fala, pode conferir ao sujeito pós-colonial um novo olhar sobre o mundo que o cerca? (Muraro 2013: 3)

Nós vemos o livro mais como um livro de aprendizagem e prendimento e pretendemos mostrar que esta poesia tem muito a ver com a chamada poesia nonsense, com fábulas populares e, mais ainda, com um movimento checo designado de poetismo. 
O mundo de Ondjaki é habitado por seres fantásticos como flores, lesmas, formigas ou sapos, enfim: bichos vários, entre os quais se inclui também o Homem. Esses seres, de que nós, homens, somos aliás os mais ínfimos, ganham características poderosas, super- e supranaturais. Nesse sentido podemos concordar com Cristina Muraro quando diz que "essa matéria é extraída do chão e das miudezas da natureza, para as quais as crianças têm olhar apurado. A tônica infantil desse livro encontra-se na ternura com que o poeta apreende tais elementos, humanizando-os ao ponto de integrar espectador e natureza nessa mesma ternura" (Nogueira do Nascimento 2014: 100).

A poesia de Ondjaki sabe desnudar palavras de todos os sentidos ganhos e colados na corrente do tempo e na corrente da fala. A palavra torna-se, assim, um simples som, uma imagem que pode ser usada novamente, inesperadamente, tornando-se fresca, novíssima, capaz, como tal, de mudar o sentido não só das palavras que lhe são vizinhas mas também da visão que se possa ter desse sentido. Como diz o próprio poeta:

Um modo de estarmos na literatura é não a levarmos demasiadamente a sério. Isso é outro ensinamento do Manoel de Barros, ele diz: quero libertar a palavra do seu estado do dicionário. $\mathrm{O}$ dicionário é útil, é até um livro bonito, explicativo, mas o que o poeta faz é ir além dele, é buscar o abraço e a ternura dentro da palavra. Não pode haver uma relação estática com a palavra. ${ }^{3}$

\section{Poesia nonsense}

Nonsense, qualquer coisa absurda, impossível, é um termo que conhecemos sobretudo na literatura inglesa (Lewis Caroll com a sua Alice ou Edward Lear e os seus limericks), mas também na literatura alemã (Christian Morgenstern) e na literatura lusófona (Fernando Pessoa, Cecília Meireles, Luísa Ducla Soares, José Jorge Letria e Manuel António Pina, entre outros).

Uma das características típicas da poesia nonsense é o ritmo regular, as rimas muito simples, primordialmente $a a b b c$, e uma união da forma e do conteúdo, onde cada linha ou verso contém uma informação completa. Podemos verificar como estas informações correspondem aos poemas escolhidos:

$\begin{array}{ll} & \text { Para pôr paz } \\ \bar{\infty} & \text { Libélulas avoam danças } \\ \bar{\infty} & \text { Aranhas cospem tranças } \\ \bar{\sim} & \text { Morcegos ralham noites } \\ & \text { Ursos linguam potes } \\ & \text { Rapozas agalinham-se } \\ & \text { Ondas engolfinham-se } \\ & \text { Carochinha avoa voa } \\ & \text { Preguiça dorme à toa } \\ & \text { Toupeiras entunam-se }\end{array}$

3 http://jcrs.uol.com.br/site/especial.php? $\operatorname{codn}=78382$ 
Grilos estrelam-se

Noites adescaem

Estrelas agrilam-se

Eu libelulizo-me. (Ondjaki 2002: 14)

Neste poema é tudo entrelaçado, um resulta do outro e torna-se a parte constituinte do outro. As galinhas tornam-se a parte indesmentível das rapozas, ondas são grávidas dos golfinhos. Estas imagens, além de serem lindas pesonificações, trazem também uma conotação forte da fraternidade das coisas, dos animais e de todos os elementos da natureza. E é um mundo muito natural, onde cada um dos elementos depende dum outro e no mesmo tempo é o seu enriquecedor.

Este poema corresponde perfeitamente à poesia nonsense, com as suas rimas perfeitas, com o esquema estrófico $a a, b b, c \ldots$, só que este nonsense não nos surge sem senso: as metáforas e personificações, como preguiça que dorme à toa, rapozas que se agalinham e ondas que se engolfinham, são formulações claras, próprias de uma mente infantil, revelam-se carinhosas e ao mesmo tempo anedóticas. E a última frase Eu libelulizo-me é de uma indesmentível beleza eufónica.

O início da poesia seguinte faz pensar, pela associação das palavras pio e piar, no célebre poema nonsense de Fernando Pessoa Poema Pial. Mas dificilmente podemos afirmar que esta alusão haja sido intenção do autor.

\section{Mas existe?}

Existe o piar do pio?

O bater da asa

É um desinstante

A passarada

Faz passar ar

Ou passeia no ar

Existe palhintimidade num aninho

De mãezinha para filhinho

A transição da minhoca

É alimentação ou incesto

O pássaro

Ganhou enjoo para chão

De tanta entrada e saliência

Aporta do aninho

foi renominada:

Simples janela arredonda.

De tanta percusação

O pássaro discipulou-se ao sapo.

Assim exista a passipiência. (Ondjaki 2002: 25)

A conclusão do poema é surpreendente, quando ao sapo é atribuida sapiência, pela figura etimológica, e depois, pela composição das palavras, da união com pássaro surge passipiência. 
A beleza advém não somente da forma e da linguagem poética, mas também do conteúdo, que prenuncia a possível união de seres diferentes e o resultado positivo dela decorrente.

Este poema mostra-se propício para falar dos neologismos como da marca característica da poesia de Ondjaki. Aqui a maioridade das inovações liguísticas é criada a partir dum cruzamento lexical que resulta da aglutinação de duas bases, para formarem uma nova unidade lexical. Como por exemplo palha - intimidade - palhintimidade, pássaro - sapo - passipiência. Estes neologismos conseguem através dum alargamento das conotações, uma imagem da ligação ainda mais estreita dos elementos da natureza e dos homens e bichos. Outro tipo da criação inovadora é a afixação (desinstante) que Ondjaki utiliza para amplificar as categorias e criar conotações e metáforas inéditas.

\section{Fábulas}

Como já foi dito, na coletânea Há prendisajens com o xão há também poemas que remetem para fábulas: os animais, as plantas ou objetos inanimados apresentam características humanas e apontam para uma conclusão moralizadora ou um ensinamento instrutivo:

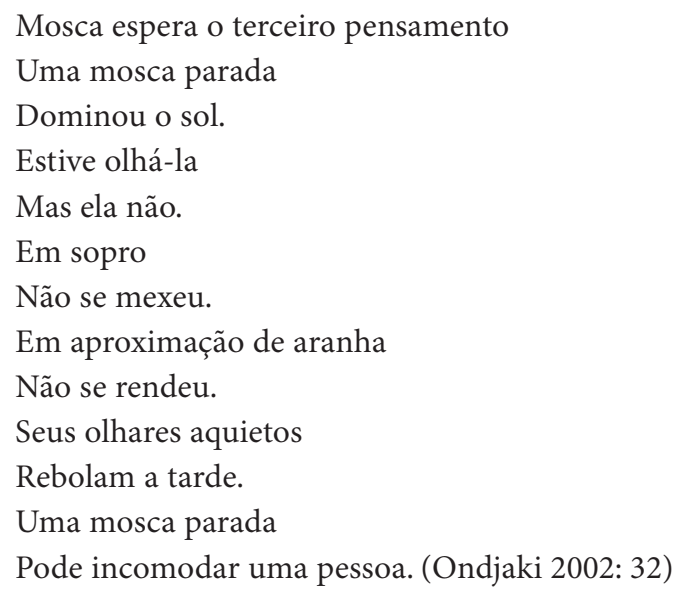

Se procurarmos os traços da fábula, vemos que o animal - a mosca, neste caso - adquire características humanas; há um certo humor e, no fim, também um ensinamento - mas não tanto para o Homem como para a mosca: não fiques parada, já que um homem pode ficar incomodado e nunca se sabe o que poderá vir a fazer. 


\section{Poetismo}

Poetismo é um movimento literário e poético que nasceu em Praga em 1923, por iniciativa dos poetas checos Vítězslav Nezval e Karel Teige ${ }^{4}$. Foi inspirado pelo dadaismo e podemos vê-lo como uma forma muito original de surrealismo ${ }^{5}$. Segundo o Manifesto do Poetismo ${ }^{6}$ por eles criado, a arte que o Poetismo faz é ligeira, algo brincalhona, amorosa e anti-heróica. Nasceu de uma atmosfera de pura amizade, de amor pela vida, e é apenas e puramente felicidade, encanto, magia, a capacidade de (se) perder (n)o tempo, um canto do coração, a beleza da poesia sem intenções, sem frases eloquentes, sem sentidos profundos, um jogo de belas palavras, uma combinação de imaginações e imagens. Não funciona sem liberdade e os poetas são menos filósofos e pedagogos e mais acrobatas, palhaços e bailarinos. O Poetismo é, no sentido mais cativante da palavra, a arte de viver, um epicurismo modernizado. A sua estética não proibe nem ordena nada. É um modus vivendi. É função da vida e ao mesmo tempo cumprimento do seu sentido. Não traz exigências e é pacífico. Não perceber o Poetismo é não perceber a vida! (Teige1971: 554-564)

Estas características correspondem na perfeição com as palavras da carta de Manoel de Barros a Ondjaki onde escreve acerca do livro Há Prendisajens com o Xão: "Há em você a consciência plena de que poesia se faz abandonando as sintaxes acostumadas e criando outras. São as palavras que guardam a poesia não os episódios. Palavra poética não serve para expressar ideias - serve para cantar, celebrar" (Ondjaki 2008: 67).

Os poetistas checos, por seu turno, já não queriam falar da guerra, nem dos problemas do pós-guerra: queriam só ver a poesia na vida, brincar com ela, criar jogos, imagens e associações agradáveis, repletas de beleza. Achamos que estas intenções são muito parecidas com as de Ondjaki:
Para vivenciar nadas
Borboleta é um ser irrequieto.
Para vestes usa pólen.
Tem um cheiro colorido
E babas de amizade.
Descola por ventos
E facilmente aterriza em sonhos.
Borboleta tem correspondência directa
Com a palavra alma.
Para existir usa liberdades.

4 http://bohemica.free.fr/poetisme/poetisme.htm

5 http://www.cnrtl.fr/definition/po\%C3\%A9tisme Mouvement littéraire et artistique tchèque, inspiré du dadaïsme et originaire de Prague (troisième décennie du XXes.). Bien que son manifeste soit paru quelque temps avant celui d'André Breton, il est évident que le poétisme est la forme tchèque du surréalisme, mais forme très originale, comme l'a bien montré Nezval, qui prétend « cultiver la rime pour en faire jaillir des éclairs nouveaux, tâcher d’obtenir des étincelles des assonances, essayer des rythmes insoupçonnés, subordonner l'image au jeu du vers et de la rime alors que les surréalistes travaillent avec l'image sans autre accessoire technique » (Arts et litt., 1936, p. 50-56).

6 http://www.pritomnost.cz/en/salon-en/866-the-second-manifesto-of-poetism 
Desconhece o som da tristeza

Embora saiba afogá-la.

Usa com afinidades

O palco da natureza.

Nega maquilhagens isentas

De materiais cósmicos. Como digo:

Pó-de-lua, lápis solar

Castanho-raiz, cinzento-nuvem.

Borboleta dispõe de intimidades

Com arco íris

A ponto de cócegas mútuas.

Para beijar amigos e vidas ela usa olhos.

Borboleta é um ser

De misteriosos nadas. (Ondjaki 2002: 38-39)

Esta poesia é como se fosse um manual de instruções para "reanimar nada", como de nada fazer tudo graças à borboleta. Todas as especificidades da borboleta, que podem ajudar no cumprimento desse objetivo, são nomeadas aqui, uma após outra: Tem um cheiro colorido, babas de amizade, desconhece o som da tristeza, dispõe de intimidades com arco íris e para beijar amigos e vidas usa olhos. A importância que é atribuida às cores refere à diversidade dos seres e juntamente com a leveza de ser da borboleta é estreitamente ligada com o senso e sentimento da amizade.

O poema seguinte, ao contrário não tem como motivo principal a leveza mas sim o peso, a lentidão, a firmeza. A ligação entre o homem e a natureza que aqui existe não é a da amizade mas a das raízes, da volta para a essência.

\section{Chão}

Apetece-me des-ser-me,

Reatribuir-me a átomo.

Cuspir castanhos grãos

Mas gargantadentro,

Isto seja: engolir-me para mim

Poucochinho a cada vez.

Um por mais um: areios.

Assim esculpir-me a barro

E re-ser chão. Muito chão.

Apetece-me chãonhe-ser-me. (Ondjaki 2002: 11)

Neste poema, podemos perceber o jogo dos sentidos no caso de des-ser-me e descer como a vontade de degradar, mas também não existir; ou descompor-se, analisar-se, ir até ao fundo das descoisas, fazer-se muidinho, ínfimo. A favor desta interpretação fala também o fim do poema - e re-ser chão. Muito chão. Apetece-me chãonhe-ser-me. Neste sentido vemos que o poema é cíclico, como a vida humana: ao des-ser se, ao engolir-se, e em seguida, ao tornar-se chão, como se se fechasse o círculo da vida, na paráfrase da Bíblia - "porque és chão e ao chão tornarás". 
A coletânea dos textos poéticos Há Prendisajens com o Xão é habitada pelos seres mais fantásticos, mais bizarros e ao mesmo tempo mais comuns: lesmas, sapos e toupeiras proferem discursos filosóficos, pairam no céu estrelado e explicam a essência do mundo.

Para o leitor melhor perceber a existência destes seres fantásticos, bem como diversos fenómenos naturais e sensações humanas, Ondjaki criou no fim do livro um pequeno dicionário com o nome Bichos convidados de A a Z. O poeta explica aos leitores os seus pensamentos, às vezes deveras complicados pelos seus neologismos e outros termos fabulados que usa para as suas invenções poéticas, e troca a poesia infantil pelas considerações filosóficas sobre o sentido da existência humana no planeta. Pelo modo como atribui aos seres mais vulgares as características mais fantásticas, alarga também as capacidades humanas de as receber, perceber e utilizar.

Este „paradicionário“ reune todas as três influências - a das fábulas, a da poesia nonsense e algumas afinidades com o poetismo checo. Veja-se um exemplo:

Pirilampo: ser que alumia um mundozito da cada vez e ajuda poetas e encontrar iluminossílabos desprovidos de grande significação. (sabe por que minha luz é tão mínima é que estou procurar coisa dentro de mimmesmo...) (Ondjaki 2002: 59)

Os inspirados neologismos, como iluminossílabos, transportam consigo um sentido de iluminação da poesia, ou da iluminação pela poesia, sobretudo, quando se quer procurar dentro do eu.

Exemplo seguinte até faz pensar num conto da fadas:

Borboleta: pratica voos ébrios, mas vive sobriamente. Se cheirada liberta o odor da amizade. A partir de suas asas podem ser construidas palavras amarelas. (Ondjaki 2002: 56)

Nestes exemplos podemos ver os traços das fábulas (lesma sábia), mas aqui é o chão que é personificado ao estar íntimo com a lesma. A ligação entre a lentitude e o conhecimento é também a destacar.

Lesma: mestre em tudo que acuse molhadez, é dona de uma vivência lentadinosa - o que reproduz intimidades com o conhecimento. Consegue alcancar tacto íntimo com todiqualquer chão. De tanto imitar a noite ficou negra. (Ondjaki 2002: 57)

Libélula: mestranda em liberdade e voo livre. Também chamada de heulibélula, ganhou aversão à pacatez. (Ondjaki 2002: 58)

Nota-se de imediato que a libélula é um dos seres mais amados pelo poeta, atribuindo-lhe características tão básicas e importantes como a liberdade e a aversão à pacatez.

Os dois exemplos seguintes explicam como um ser pode causar um desconforto dos outros sem querer ou sem se mesmo aperceber disso:

Mosca: nunca reconhece o mau cheiro, embriagada que vive. (Ondjaki 2002: 58) 
Urso: um desatento pisador de flores. (nem é por mal; para mim as flores servem é para alcatifar o mundo). (Ondjaki 2002: 60)

E no fim não falta também uma inspiração intertextual: Ondjaki não pode se esquecer de falar das suas inspirações literárias - dos seus camaradas e colegas escritores:

Despalavreação: é um ensinamento. Uma desaprendizagem, em desmomento. E tem outros nomes: guimarães prosa, manoel de barro, luuandino vieira, mia conto, ou qualquer ser humano que sorria no gigantesco significado das coisas insignificantes. (Ondjaki 2002: 64)

A palavra despalavreação refere a descomposição do pensamento rígido e automatizado que só através da recomposição subsequente pode aprender novos sentidos e novas sensações. Os escritores escolhidos como representantes desta desaprendizagem são o prosador Guimarães Rosa e poeta Manoel de Barros (poeta de pantanal) ambos os brasileiros e os autores africanos, contista Mia Couto e José Luandino Vieira (autor da coletânea dos contos Luuanda).

E no final, o gigantesco significado das coisas insignificantes podemos tomar como a perfeita característica da poesia de Ondjaki.

\section{Considerações finais}

Este texto focalizou o objetivo de servir como excursão guiada pela terra fantástica da poesia do jovem poeta angolano Ondjaki e, sobretudo, pelo seu livro de poesia Há Prendisajens com $o$ Xão. Esta terra fantástica é habitada por personagens muito poéticas e no fundo tão vulgares, como lesmas, moscas ou sapos. Através das explicações sobre estes seres, a terra e os seus sentimentos e sensações, o autor abre a sua veia poética infantil, explica sem preconceitos e sem informações pré-recebidas significados de fenómenos naturais e de sentimentos humanos, abrindo-nos, assim, um mundo amplíssimo de sentidos de palavras fantásticos, simultaneamente voadoras e nadadoras, deste modo atribuindo aos seres vulgares qualidades super- e supranaturais, como andar nas nuvens ou ensinar o céu a andar a pé. Como diz também F. C. M. Nogueira do Nascimento:

Aqui a infância encontra lugar em neologismos e surpreendentes relações sintáticas, pelas quais se fortalece a poetização do espaço e da convivência com personagens do cotidiano de Ondjaki, seja como poeta, seja como leitor de outros poetas e culturas. É a gratuidade da infância que retorna como uma mudança de rumo no mundo do objeto útil, da técnica como forma de moldar a sobrevivência cinzenta. Nesse sentido, a poesia de Ondjaki propõe uma (re)aprendizagem do estado de infância e de poesia como um modus vivendi. (Nogueira do Nascimento 2014: 101)

Mostramos que a poesia de Ondjaki, sobretudo na coletânea Há Prendisajens com o Xão, coresponde em muitas características à poesia nonsense, às fábulas e também ao poetismo checo. Sendo antipolítico, o Poetismo já não quer falar das guerras e Ondjaki na sua poesia, diferentemente da maioria dos seus colegas, também abandona histórias da antiga Angola durante 
e depois das guerras, não solucionando questões de identidade e angolanidade. Tal como os poetistas checos, procura só a leveza de ser, a beleza dos versos e das imagens.

Podemos concluir com F. C. M. Nogueira do Nascimento:

Assim, pode-se pensar que a construção da identidade literária de Ondjaki, vista de dentro do contexto angolano que o precedeu, dá-se não pela necessidade de manter-se fiel ao código até então utilizado, mas em buscar comunicação com uma rede cultural ampla, sem deixar de colocar-se como sujeito de voz própria: marcações perceptíveis na forma como a palavra corporifica seu sentido fônicosemântico, organizado e grafado hibridamente, como o próprio título da obra já sinaliza. (Nogueira do Nascimento 2014: 98)

De qualquer modo, a poesia do Ondjaki mostra-nos novos mundos, abre-nos novos caminhos para novas realidades, explica-nos novos sentidos de palavras, novas dimensões da natureza e inesperadas características dos elementos naturais e de nós mesmos.

\section{Referências bibliográficas}

Muraro A. C. (2013). Um Menino com a Boca Suja de Poesia. Nau Literária vol. 09, n. 01, 1-7.

Nogueira do Nascimento F. C. M. (2014). Territórios da Infância em Ondjaki: Uma Estética da Pós-colonialidade Angolana. Revista do Núcleo de Estudos de Literatura Portuguesa e Africana da UFF, 6, 13, $2^{\circ}$ sem., 95-104.

Ondjaki. (2010). Dentro de Mim Faz Sul Seguido de Acto Sanguíneo. Portugal: Caminho.

-. (2002). Há Prendisajens com o Xão (O segredo húmido da lesma \& outras descoisas). Portugal: Caminho.

-. (2004). Outras margens da mesma Língua. Comunicação lida na conferência A Língua Portuguesa: Presente e Futuro, Lisboa, Fundação Calouste Gulbenkian, 2004-12-10.

-. (2009). Materiais para Confecção de um Espanador de Tristezas. Portugal: Caminho.

. (2015). Os modos do Mármore. Portugal: Através editora.

Teige K. (1971). Poetismus. In Avantgarda známá neznámá (vol. I) (pp. 554- 564) Praha: Svoboda.

$<$ http://bohemica.free.fr/poetisme/poetisme.htm>

$<$ http://homoliteratus.com/entrevista-com-o-escritor-angolano-ondjaki/>

$<$ http://jcrs.uol.com.br/site/especial.php?codn=78382>

$<$ http://www.pordentrodaafrica.com/cultura/o-continente-africano-tem-uma-forca-cultural-gigantescaespero-que-possamos-deixa-la-acontecer-diz-ondjaki>

$<$ http://www.pritomnost.cz/en/salon-en/866-the-second-manifesto-of-poetism> 